Lacan, no seminário sobre a relação de dojeto, diferencia claramente as três dimensões do pai, e acentua opai real, consideradb, a partir do caso do Pequeno Hans, como o agente da castração simbólica. Esta função é examinada aqui por meio de das situaçães clínicas, a de um adolescente para quem a emergência tardia de um real do pai induz a um surto delirante, eade uma mulher que, confrontada à esterilidade do marido, procura o pai numa pluralidade de figuras. Pai-rel; castração; psicopatologia; psicanálise

THE REAL FATHER Lacan, inhis seminar abat the relation of doject, differsclearly the three dimensions of the father andaccentuate the real father, considered, thragh the case of Little Hens, as the agent of the synbolic castration. This findion is examined here through thoclinical situation, of one teenager in which the latesunface of areal fatherconduts toa deliriaus attoreak, and of cne woman that, confronted with her holardsteri7ity, searchesher father fora pluralityoffigures. Father-real; castration; psychopathology; psychomalysis

\section{O ENIGMA DO PAI REAL}

\author{
Jean-Jacques Rassial
}

$\mathrm{U}$ a das dificuldades em dizer-se lacaniano é o fato de que na dora de Iacan há, ao mesmo tempo, uma continuidade - os mesmos significantes, uma vez prootuzidos, atravessam toda a sua obra - e uma descontinuidade - quanto ao valor conceitual e qperatório desses significantes, particularmente segundo as modelos, lingüristico e lógico, ótico ou topológico em que se inscrevem. Assim, Simbólico, Real e Imaginário, de acordo com os momentos, são pensáveis ou como campos substanciais com consistência própria, ou como as categorias pelas quais o sujeito falante atribui-se, ou não, o mundo e a língua, ou como as dimensões modais de um Real em que se inscreve o falasser sexuado, de tal modo que não somente sua hierarquia lógica, até mesmo genética, varie, mas também sua extensão e sua compreensão.

Isso é ainda mais sensível quando se trata de qual ificar o pai: o pai simbólico, aja real ização na operação nome-do-pai muda de valor com a passagem tardia para o plural dos nomes-do-pai; o pai imaginário, diante de quem, segundo Lacan, no Seminário sobre a Relação de objeto (1994) , "'nos encontramos o tempo todo", deixando aberta a questão de saber se Freud, com o Pequeno Hans, vem ocupar o lugar do pai imaginário ou o do pai

Professor da Provence, Universidade em Aix-Marselha 1, diretor do laboratório de psicopatologia clínica e psicanálise nesta universidade. Psicanalista membro do Espace Analytique. 
simbólico; sobretudo esse "pai real", ao mesmo tempo o "coitado" da realidade e agente da castração simbólica, mas que não terá mais o mesmo sentido se nos referimos a Televisão (1975) ou o Seminário sobre O sintama (inédito) . Segundo Iacan, seria interessante comparar o caso Hans e o caso Joyce, em função de uma mudança de concepção do pai e do real.

Mas permaneço por enquanto na já difícil compreensão desse "pai real" no Seminário scbre A relação de objeto. Utra vez constatado que "o pai simbólico é uma necessidade da construção simbólica, que podemos situar num além, eu diria quase de transcendência", e que, assim, "não está representado, no fim das contas, em nenhum lugar", em todo caso não no quadro construído progressivamente por Lacan em seu Seminário, da mesma forma que não são representadas, notemo-lo, a mãe real e a mãe imaginária; poderíamos assim pensar que é mais por uma preocupação com a coerência lógica de um quadro cartesiano do que por uma verificação clínica que este pai real, do qual "a criança pôde ter apenas uma difícil apreensão, em função da interposição dos fantasmas e da necessidade da relação simbólica" (p. 143) , situa-se num lugar de agente da castração simbólica.

De fato, primeiramente, indecisão fintífera, Lacan evoca nesse "pai real", ao mesmo tempo, aquilo que seria sua dimensão real do pai e aquilo que resultou do pai cotidiano da realidade, e, em seguida, demonstra, mais pelo absurdo, que esse pai real fracassa em ser um verdadeiro pai agente da castração, e Lacan é levado então a designar esse pai eficiente como aquele que "preencheria sua função imaginária", pois é uma "carência do pai imaginário, do pai realmente castrador" a que o Pequeno Hans deve suprir. Em terceiro lugar, na clínica, podemos ter a impressão de que quando aparece o pai real, detentor do pênis real, ou o papai do cotidiano, "em sua forma concreta, empírica, e eu diria quase degenerada", isso parece ter efeitos devastadores, ou pelo menos problemáticos, mais do que fundadores.

Mais do que me estender sobre um comentário do texto de Lacan, gastaria de propor dois exemplos clínicas: por um ladb, o caso de um adolescente que acompanhei, há alguns anos, após um surto delirante dismorfofóbico relativo aos órgãos genitais, sem que se instalasse uma psicose; por outro lado, o caso de uma mulher, confrontada com a impossibilidade de engravidar, questionando diretamente não apenas o que seria do pai, mas o que seria das três pais possíveis, mais um.

A esse adolescente daremos o nome de "Filhão" (Fiston), que se aproxima de seu sobrenome, e a seu pai chamaremos de "Filhão-pai". Reconstituindo elementos de seu discurso, evoca- 
remos um episódio que ocupa várias sessões e que tem um papel determinante em sua análise. Eu já o recebia havia várias semanas, quando, ao final de uma sessão, ele tira dinheiro de sua carteira, e dela caem preservativos. Ele os recolhe rapidamente e sai sem me dar tempo de dizer nenhuma palavra. $\mathrm{Na}$ sessão seguinte, ele falou de uma cena ocorrida apenas alguns dias antes do início de seu surto delirante, da qual ele nada havia dito até então.

Seu pai, prudente, muito prudente, constatando o engajamento de seu filho de 16 anos numa vida sexual, havia considerado como produtivo, nos tempos atuais, discorrer, face a face, sobre a ut i lização sistemática de preservativos. Durante esse discurso, Filhão-pai escolheu uma imagem e uma palavra: "É como se cobrir para se proteger, cobrir-se com um impermeável" . Apesar de ser um significante-mestre, este "imper", em sua polissemia fonética, foi para Fi lhão, pelo menos retrospectivamente, um significante-choque. E seu pai continuou, numa conversa que ele pretendia que fosse de "homem para homem", evocando suas próprias dificuldades em fazer uso de preservativos, escolhidos como meio de contracepção, "antes do nascimento de seu filho", ressaltando que no início isso poderia impedir uma ereção, mas que é um "inconveniente necessário" a que acabamos por nos habituar.

Nás sessões seguintes, várias pistas prolongaram essa evocação. Primeiramente, para constatar que foi preciso que ele passasse pela experiência de não ser atendidb, apesar de sua insistência, em seu pedido, feito por intermédio dos pais, de conselhos para transpor e reparar sua vivência de loucura, para que pudesse me falar sobre essa história; ficou explícito para ele que eu não era aquele que produziria o mesmo efeito, nem aquele que o consolaria. Em seguida, ele atribuiu a essa troca com o pai um papel determinante no advento de um episódio delirante, no sentido de que assim ficavam acentuadas, ressaltadas, suas dúvidas de adblescente, por um ladb, sobre a qualidade da atual relaçãa sexual entre seus pais, e, por outro, no registro de um romance familiar elaborado anteriormente durante a puberdade, menos sobre a paternidade real de seu pai - dúvidas sem fundamentos realistas - do que sobre o desejo ou não desejo de terem uma criança por parte de seus pais, na ocasião de seu nascimento. Elle evocou, sobretudo, em seus fundamentos, a função patema.

Considerando tratar-se aqui do pai real, o problema reside em que este aparecimento intempestivo, e em função do efeito de surto delirante, repetiu, não uma castração simbólica, mas uma privação real, explicandb a conseqüência, se não psicótica, ao menos 
psicotizante dessa emergência; ora, segundo Lacan, na privação real, o agente seria o pai imaginário, e o abjeto, o falo simbólico. Mas, por um ladb, este surto delirante foi isoladb, e não uma via de acesso à psicose, e, por attro ladb, este aparecimento tardio na adolescência era secundário a uma outra existência dopai real.

Filhão evocou então o que era esse pai em sua infância, e, do lado do pai real, cito uma formulação corrente: era ele que "parava" seu filho en seus "extravasamentos" de conduta cu de afeto, quandb, criança, ele se deixava tomar por suas bobagens, suas iras, suas teimosias, e o pai conseguia isso, dizia Filhão, não por meio da voz grossa ameaçadora de que ele fazia uso raramente, nem por uma autoridade que lhe era reconhecida na família, mas simplesmente por sua presença: "Ele estava ali quanob era preciso, e isso bastava para me acalmar ou para me dar confiança", como uma encarnação do limite. Isto me faz lembrar duas idéias que se aplicam ao pai real: Mustapha Safouan (1973), no capítulo dos "Estudos sobre o Édipo", no que diz respeito ao pai real, dá como "sentido da função paterna... o de tomar para si a angústia da criança", tendo esse pai real um papel de mediação em relação à angústia que, graças à sua existência, não é mais insensata; Françoise Dolto, em Imagem inconsciente do corpo (1982), insiste na idéia de que a castração não pode ser "dada" com eficácia, a não ser por aquele que a ela também foi submetido; assim, o pai real não seria scmen- 
te agente da castração, mas também sujeito da castração, mostrando que é possível ser, sem que isso constitua um desastre, sujeito submetido à castração.

A adolescência é sempre um momento em que se separam, de modo mais ou menos dramático, pai real, pai imaginário e pai simbólico - como, aliás, as diversas dimensões da mãe - , quando os pais revelamse necessariamente não qual ificados para conjugar esses três valores e encarnar de modo válido um Outro em que os ideais encontram sentido. Ora, o que acontece aqui é a subst ituição do trabalho psíquico do adolescente por uma intervenção intempestiva do pai, da qual diríamos indicar menos as qualidades de um pai real do que a dimensão real do pai imaginário.

Se algo do pai real vem ocupar - lugar de agente da castração simbólica, é no encontro de um real do pai que mostra suas próprias falhas, real do pai que, por aparecer, conduz mais à derelicção do que ao desastre. Parece-me ser a ambigüidade que persiste ainda, em 1957, na abordagem de Lacan, quando este qual ifica como real esse pai da realidade, que deve, apoiado no pai simbólico, pai morto sem encarnação possível, a não ser mítica, e dando lugar ao pai imaginário, "ao qual se refere mais comumente toda a dialética, a da agressividade, a da identificação", ir ao encontro, e atémesmo de encontro à criança, a título de detentor desse "pênis real" também rapidamente destronado do lugar fálico a que foi alçado para valer como signo da diferença sexual.
Certamente Lacan nos mostra de que modo o pai do Pequeno Hans não é válido a esse título, ele recua diante de sua dupla missão, castradora e fundadora, mas, à exceção de nos lamentarmas sobre o declínio da função paterna, que indica mais a perda de consistência imaginária do pai simbólico, não deveríamos considerar que manter esse lugar de pai real é, dizendo propriamente, impossivvel, no sentido em que esse real atribuído ao pai, imediatamente o despatemaliza. "Seja um verdadeiro pai" , é a demanda singular do pequeno föoico, ou então, antecipando um desprendimento que terá valor e função na adolescência, não seria a passagem dorigatória de cada um? Esse lugar de agente da castração simbólica não seria um lugar lógico que nenhum sujeito pode ocupar? Lembremos simplesmente que, se há piores que outros, não há bons pais. Talvez por esta razão Lacan irá abandonar essa pista dos agentes da falta para dar lugar, somente, mais tarde, aos agentes dos disarirsas.

Passemos à segunda vinheta clínica para questionar esta função do pai real. O fato de ter proposto, o que faço raramente, uma regra de abstinência a Madame Lainé, teve como efeito sua renúncia provisória em começar uma análise. De fato, ela estava às voltas com um processo de inseminação artificial, dita com doador, mas, veremos, um pouco mais complicada, pois motivada pela esterilidade de seu marido. Ela voltou alguns meses depois, com um relato em que se condensava sua questão sabre o pai. 
Na falta da análise, ela teve um amante psiquiatra, amigo de seu marido homeopata, e encontrava-se com ele num hotel em Paris, do qual mudarei o nome nesta história ligeiramente modificada - Hotel Ideal, Rua dos Três Irmãos. Por pouco deixaram de se encontrar, pois Madame Lainé mudou esse nome, ao transmiti-lo a seu amante, para "Hotel Único, Rua dos Santos Padres". Esta só pôde então constatar o quanto estavam vivos os conflitos que motivaram sua primeira demanda.

De fato, o aspecto estranho dessa inseminação, que teve como único resultado o de fazer do ginecologista o cúmplice de sua infidelidade, aliás, pouco eficaz, era que os doadores não eram anônimos; eram os três irmãos de seu marido, com as cumplicidades que se podem imaginar. Assim, podia-se enumerar uma seqüência de pais virtuais para essa criança impossível: o maridb, os três irmãos, o amante, o ginecologista e, por que não, o psicanalista, pelo menos durante os primeiros encontros. Pais que ela podia imaginar para esta criança, ainda que seu desejo de ter um fil hho não transparecesse com evidência.

Chegamos rapidamente aos dados de seu próprio nascimento: segunda filha de sua mãe, sendo o primeiro filho, um menino, gerado num estupro aparentemente ligado à guerra e abandonado primeiramente aos cuidados da família, com a qual ela rapidamente rompeu. Da parte de seu pai, que não a reconheceu, mas que a manteve até a maioridade, havia igualmente uma história de guerra: ele havia perdido suas duas filhas durante um bombardeio, e Madame Lainé tinha o nome de uma de suas filhas. Casou-se novamente, sem fi lhos, mas teve fi lhos com duas autras mães diferentes.

Um outro elemento, rapidamente constatado, refere-se ao fato de que, com raras exceçães, toobs as homens de sua história eram médicos, ou ligados à saúde, depois de um grave problema que fez com que ela preterisse seu marido por uma relação mais passional. Além deste sinal de sua histeria, parecia estar em jogo aí toda uma problemática do corpo, menos do próprio corpo do que desse corpo reconstituído sob o olhar do pai.

Relato esse caso, não para distribuir as funções patemas, usando essa multiplicidade de encamaçães possíveis: seu próprio pai, o marido, as três irmãos, o amante, até mesmo o psicanalista ou o médico como figura ideal. De fato, para cada um desses personagens, trata-se ao mesmo tempo de existir em várias dimensões, mas não em todas; como ela não é nem perversa, nem psicótica, esta distribuição não lhe assegura nenhuma plenitude à moda de Fourier.

Seu pai, de que ela tece um retrato grandioso, tem o papel de um pai imaginário (o do romance familiar) e o de um pai real, 
mas, tendo-Ihe dado apenas um nome que ela rejeita como sobrenome, falha no simbólico.

O marido, sustentando o pai simbólico e apoiado no próprio real por seus irmãos, toma-se imaginariamente uma figura pálida, de quem mais tarde ela irá se separar.

Os três irmãos só existem no real e no imaginário, pois, simbolicamente, são sustentados pelo marido, que, ainda que caçula, representa o chefe de famúlia.

O amante, de certo modo, só tem uma existência sintonática, sinal das falhas real, simbólica e imaginária, e remetido à sua impotência em ser marido, genitor ou guardião de um saber.

Quanto ao psicanalista ou ao médico, estes são figuras imaginárias e lugares do saber sobre o pai simbólico, mas deixam o real fora de seu alcance.

Aquilo que Madame Lainé testemunhava, que apareceu essencialmente na comparação entre seu destino e o de sua mãe, além do singular em sua história, é que não há atro pai unificadb, além do pai simbólico, que só pode ser encamado por um pai ao preço de sua morte, de sua ausência ou de seu interdito. Na configuração dos "pais" de sua existência, qualquer autro pai além desse pai morto, ausente, interdito, só poderia ser decadente, pelo próprio fato de sua patemidade virtual, e mais ainda porque cada um deles mostrava sua falha, sua castração, com insistência. Isto apareceu principalmente quando ela encontrou um homem por quem se apaixonou, mas que tinha apenas um defeito, 
segundb ela, não o de ser casadb, mas o de já ter filhos. Evidentemente, preferiu um novo médico.

Se o pai da realidade é um "coitado", e que ele apareça como tal num dado momento, na adolescência ou quando se põe para o sujeito a questão de ter um filho, por mais que, durante $a$ infância, ele tenha "agüentado", para retomar a expressão de um jovem futuro pai confrontado a esta imagem, é que o pai real só deve ser concebido como uma dimensão da patemidade, enquanto tal não encamável por uma figura única e unificada; se o pai da realidade é o agente da castração simbólica, é porque, enquanto pai real, está ele mesmo submetido a ela, e, portanto, denuncia este próprio real que sustenta sua existência, em benefício de uma enunciação que faz prevalecer a ordem simbólica; isto pode ser muito bem avaliado na ocasião da circuncisão ritual judaica ou muçulmana. A emergência de um real é, portanto, apenas um momento, lógico e genético, que não permite a um sujeito encarnar-se, au ser encamadb, nesse lugar.

\section{REFERÊNCIAS BIBLIOGRÁFICAS}

Dolto, F. (1982) . L'image inconsciente du conps. Paris: Sevil.

Iacan, J. (19/5) . Télévision. Paris: Sevil. (1994). Ie sáminaire, Livre III, La relationd'objet. Paris: Seuil. Ie séminaire, Ie sinthame. Inédito, notas.

Rassial, J. J. (1999) . Ie sajet enétat limite. Paris: Denoël.

Safouan, M. (1973) . Études sur l'CFdipe. Paris: Sevil.

Recebidb em agosto/2003.

Aceito em dezembro/2003. 